\title{
Making early childhood count
}

\section{Clyde Hertzman MD MSc, Robin Williams MD}

A strong case has been built in support of the importance of early child development based on the "new neuroscience." $1-3$ We now understand that health, emotional well-being and life success have their roots in early childhood. This has implications for all countries that are signatories to the United Nations Convention on the Rights of the Child because each of these countries is responsible for providing children with the opportunities necessary to develop physical, cognitive, social and emotional capacities in early life. ${ }^{4}$ In this article, we discuss the approaches that can be used to monitor early childhood development.

An ongoing flow of high-quality information about the state of early child development, its determinants and longterm development outcomes is essential for fulfilling these commitments. The importance of developing measures of early child development at a population level should be selfevident if we believe that "what gets counted, counts." With counting comes a focus on issues, public dialogue and resources. Thus, monitoring early child development - across a population, over time and with the ability to examine geographic trends - is a key activity in support of the success of a modern developed society.

Physicians have long worked at the individual child level, taking physical and developmental measurements and comparing them with norms. But apart from measuring infant mortality rates, mean birth weights and the rates of some selected diseases, little has been done at a population level to examine the support and programming for mothers and young children at the community, regional or national level. As a consequence, it is impossible to verify claims that Canada or any country is committed to early child development.

A coordinated system of statistics on early child development is the most desirable approach for a robust surveillance system. Such a system should be population-based, personspecific and longitudinal. It should encompass data that can be linked at the level of the individual, the social environment (the home) and the group (the community), and it should include more global elements such as the economic status of parents and caregivers.

\section{Approaches to monitoring development}

\section{Social indicators approach}

The social indicators approach (Table 1) is based on the Composite Learning Index from the Canadian Council on Learning. ${ }^{5}$ This index shows lifelong learning in Canada, similar to how the consumer price index shows trends in the cost of living over time. The Composite Learning Index includes rou-

\section{Key points}

- Measurement systems are key for improved childhood development outcomes because "what gets counted, counts."

- A high-quality measurement system is critical to determining what support systems are needed for children.

- All of the components of a high-quality measurement system currently exist in Canada, but coordination, refinement and a national implementation and dissemination strategy are needed.

- An independent national children's commissioner may provide the necessary leadership and act as a focal point for change.

tinely collected data from a wide variety of sources that have the capacity to provide a national and regional snapshot that may be used repeatedly over time, without a loss of validity, to study trends and determinants of early child development.

The index combines data from several sources to generate scores that represent the state of lifelong learning in Canada. A high score for a particular area of the country indicates that the learning conditions are favourable to economic and social success. The index examines 4 major areas: learning to know (e.g., high school dropout rates, participation in postsecondary schooling), learning to do (e.g., participation in job-related training, access to learning institutions), learning to live together, (e.g., charitable giving) and learning to be (e.g., exposure to media, sports and recreation events). The Human Development Index, developed by the United Nations Development Program, is an example of this approach, and a score is calculated for all member countries.

\section{Population-based survey}

This approach uses population-wide multidimensional assessments of early child development, such as the Early Development Instrument. This instrument was developed at the Offord Center for Child Study, ${ }^{6}$ and population-based implementation strategies were pioneered by the Human Early Learning Partnership of British Columbia. ${ }^{7}$ The Early Development Instrument is a questionnaire that is completed by kindergarten teachers about their pupils. The instrument reports on 5 key domains of early development: physical, social, emotional, communication, and language and cognitive skills. Children who fall in the lowest 10th percentile for a given domain are deemed "vulnerable" in that area. Children who are vulnerable in more than 1 domain are categor-

From the University of British Columbia (Hertzman), Vancouver, BC; and Niagara Region Public Health (Williams), St. Catharines, Ont. 
ized as "vulnerable" in terms of their development upon entry to school. Data are collected for all kindergarten children in a jurisdiction, which provides detailed information at the community and neighbourhood levels, where key determinants of early child development and the best opportunities for intervention are found.

Currently, over 400000 results of the Early Development Instrument for Canadian children have been obtained, including full population coverage in British Columbia, Manitoba and Ontario. In some communities and provinces, these data are provided in a regular and meaningful way, which enables an understanding of the strengths and weaknesses of the community's early child development system. In British Columbia, over 500 community-based initiatives to improve early child development have been initiated as a result of insights provided by the Early Development Instrument. Internationally, this instrument has been used extensively in Australia and Chile. Figure 1 shows the vulnerability of children across neighbourhoods in Vancouver in 2007. ${ }^{8}$

\section{Longitudinal survey}

This approach includes the systematic follow up of a representative sample of a population of children and their families. An example of this strategy is the Quebec Longitudinal Study of Child Development, ${ }^{9}$ which entails the collection of developmentally appropriate information at regular intervals from a birth cohort that is representative of children born in Quebec in 1998. This study includes multivariate assessments of longitudinally measured outcomes of child developmental factors, as well as extended and detailed multilevel assessments of environmental factors (e.g., family socio-economic status, parents' behaviours, peer relations). Several early child development measures (e.g., the Block Design subtest of the Weschler Preschool and Primary Scale of IntelligenceRevised, the Peabody Picture Vocabulary Test and the Early Development Instrument) have been incorporated into the Quebec Longitudinal Study of Child Development. This approach is best suited for studying children's developmental trajectories and their personal, familial and environmental determinants, for establishing the timing and sequence of key developmental events and for evaluating causal claims.

\section{Linked data approach}

This approach, although well developed in Sweden, Finland, Denmark and Western Australia, needs to be strengthened in Canada. At present, both the Manitoba Centre for Health and Policy and the Human Early Learning Partnership in British Columbia use this approach. In the linked data approach, a person-specific, population-based, longitudinal data set is created by linking administrative records from multiple sources. When health care and education records from the recent past are combined, it is possible to create a historical prospective of developmental trajectories for an entire population of children, which allows for a high level of efficiency in tracking child development.

For example, Manitoba Centre for Health and Policy has merged the records of children enrolled in medicare with school records, and organized the data according to neighbourhood socio-economic status. This exercise demonstrated dramatic differences in school success rates by grade 12 depending on which records were used. Based on school records alone, it would appear that about $87 \%$ of children from neighbourhoods with low socio-economic status passed the language arts test. However, when all children born 18 years earlier still living in the province who should have written the

Table 1: Comparison of 4 approaches to monitoring early child development

\begin{tabular}{|c|c|c|c|}
\hline Approach & Data source & Data collection & Advantage \\
\hline Social indicators & $\begin{array}{l}\text { Opportunistic mixture of data } \\
\text { from various sources }\end{array}$ & $\begin{array}{l}\text { Can be collected by a small } \\
\text { staff, but finding all relevant } \\
\text { data sources and evaluating } \\
\text { their quality is time consuming }\end{array}$ & $\begin{array}{l}\text { Can be easily reduced to a } \\
\text { single, scalable number that can } \\
\text { serve as a gross domestic } \\
\text { product" of child development }\end{array}$ \\
\hline $\begin{array}{l}\text { Population-based } \\
\text { survey }\end{array}$ & $\begin{array}{l}\text { Newly collected data for a } \\
\text { population of children of a } \\
\text { given age }\end{array}$ & $\begin{array}{l}\text { With school district } \\
\text { cooperation, the Early } \\
\text { Development Instrument can be } \\
\text { used for about } \$ 15 \text { per child. } \\
\text { Data for all kindergarten } \\
\text { children in Canada could be } \\
\text { sampled and analyzed for less } \\
\text { than } \$ 10 \text { million }\end{array}$ & $\begin{array}{l}\text { Provides an efficient measure of } \\
\text { children's development at one } \\
\text { point in time. Data can be } \\
\text { analyzed at the level of the } \\
\text { neighbourhood and school } \\
\text { catchment area }\end{array}$ \\
\hline $\begin{array}{l}\text { Longitudinal } \\
\text { survey }\end{array}$ & $\begin{array}{l}\text { Newly collected data from a } \\
\text { sample of the population. } \\
\text { The sample should be large } \\
\text { enough to allow subgroups to } \\
\text { be studied }\end{array}$ & $\begin{array}{l}\text { Sufficient data must be } \\
\text { collected at the individual, } \\
\text { social and contextual level. The } \\
\text { sample size for data collection } \\
\text { should be in the tens of } \\
\text { thousands }\end{array}$ & $\begin{array}{l}\text { Provides the most detailed } \\
\text { information about the diverse } \\
\text { trajectories of children's } \\
\text { development }\end{array}$ \\
\hline Linked data & $\begin{array}{l}\text { Routinely collected } \\
\text { administrative data from health } \\
\text { care, education and other } \\
\text { sources }\end{array}$ & $\begin{array}{l}\text { Because the data already exist, } \\
\text { all efforts can go into creating } \\
\text { ethical access, data cleaning } \\
\text { and analytical techniques }\end{array}$ & $\begin{array}{l}\text { Most efficient way to create } \\
\text { basic developmental } \\
\text { trajectories that include all } \\
\text { children, especially highly } \\
\text { transient children and those } \\
\text { from nonresponsive families }\end{array}$ \\
\hline
\end{tabular}




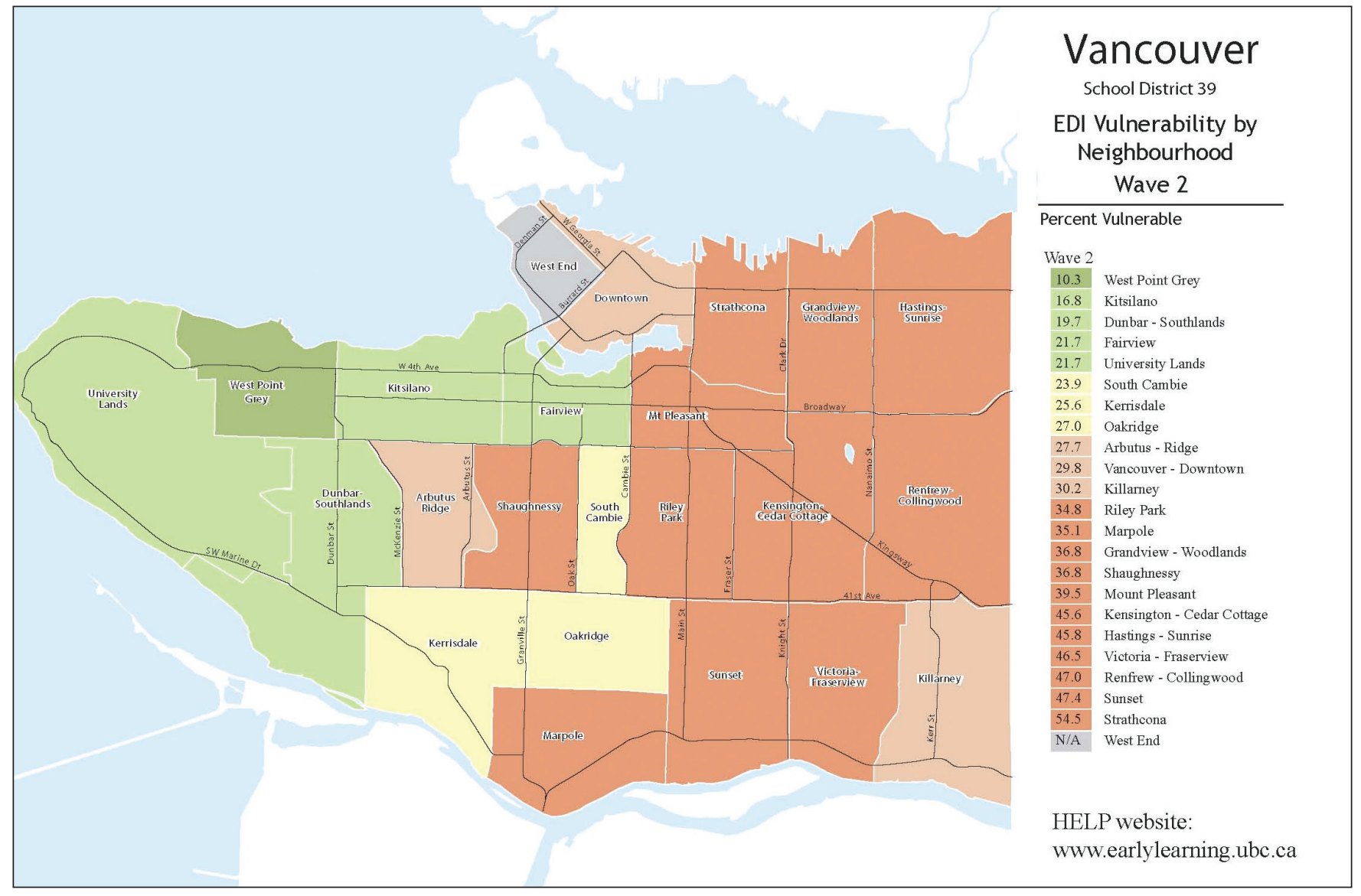

Figure 1: Proportion of children classified as vulnerable by the Early Development Instrument, Vancouver, 2007. Source: Human Early Learning Partnership. ${ }^{8}$

test were included, the pass rate for children from low-income neighbourhoods was 33\%. This approach highlights the importance of high school dropout rates $(20 \%)$ and of high retention rates: a full $27 \%$ of those living in low-income neighbourhoods had been held back in academic progress for 1 or 2 years. Most of these children failed to graduate. ${ }^{10}$

\section{Canadian early child development}

At present, no country has all 4 approaches of a system fully in place. Canada is rightly considered to be a world leader in the social indicators approach. With the development and implementation of the Early Development Instrument, Canada and Australia are currently world leaders in the populationbased survey approach. However, Sweden, Finland, Denmark and Western Australia have population-based linked data systems that far exceed current Canadian systems. The United Kingdom is the world leader in longitudinal surveys with a series of national birth cohorts (based on births in 1946, 1958, 1970 and 2000). The data from these cohorts are being analyzed in a coordinated fashion to understand both stable and changing childhood determinants of health and well-being.

The Council on Early Child Development (www .councilecd.ca) is a Canadian organization committed to turning early child developmental science into action, especially at the community level. The council supports the work of academics and researchers in creating appropriate measures of early child development using the social indicators, population-based survey, longitudinal survey and linked data approaches. Given that no country has as yet developed and used measures across all approaches, we hope that the multiple elements of evaluation will break new ground. The suggested approaches for Canada to cover the 4 domains ${ }^{11}$ could be adjusted and adapted for use in other countries struggling to measure early child development, with each country describing pitfalls and usefulness of the integrated measures.

\section{Summary}

Regardless of the industrialized country studied, all data to date reveal that most children at every socio-economic level are remarkably similar at birth. However, inequalities in development emerge early in childhood, usually before school entry. Children who are already behind their peers when they begin school will likely fall further behind. Ultimately, fully engaging these children in the educational process may be difficult. Early intervention makes a difference. ${ }^{2,3}$ It is imperative for governments to provide universal, affordable access to effective early childhood programs starting in the first few years of life, to improve the experiences of all young children 
as well as those who are most vulnerable.

Along with these interventions, an effective measurement system is required. The 4 approaches discussed here are the building blocks. Integration of data from each approach can provide the foundation for the system of early child development statistics that Canada needs as it moves forward to address the huge challenges of the future. Although no country has a robust system for measuring early child development, several countries are leaders in different approaches. By expanding and enhancing measures of early child development within a country and sharing the pitfalls and benefits of each approach, countries can more quickly address this important need and evaluate the impact of interventions.

Canada is a long way from fulfilling its promise to children and its commitments under the United Nations Convention on the Rights of the Child. Further, the lack of a robust surveillance system to better inform policy on behalf of Canada's children is unfortunate. One concrete step that may change the policy climate would be to follow the British model and appoint a federal commissioner who is empowered to sit at the Cabinet table to promote and defend the needs of children. One key role of the commissioner would be to audit the progress of Canadian children using data from the measurement system described here. Appointing a strong champion for children to such a position and providing him or her with high-quality information flows may have the potential to "tip the balance" toward child-friendlier policies and practices. This change is badly needed in Canada.

This article has been peer reviewed.

Competing interests: None declared.

Contributors: Both of the authors contributed to the content of the article, revised it critically and approved the final version submitted for publication.

Acknowledgements: We thank Dr. Ray Peters, Dr. Michel Boivin and Leanne Boyd for their review and comments on this article. We also thank Jane Bonaldo for administrative support.

\section{REFERENCES}

1. Keating DP, Hertzman C. editors. Developmental health and the wealth of nations. New York (NY): The Guildford Press; 1999.

2. McCain MN, Mustard JF. Reversing the real brain drain. The early years study, final report 1999. Toronto (ON): Publications Ontario; 1999.

3. McCain MN, Mustard JF, Shanker S. Early years study 2: putting science into action. Toronto (ON): Council for Early Child Development; 2007. Available: www.councilecd.ca/cecd/home.nsf/pages/EYS2.html (accessed 2008 Dec 1).

4. United Nations Committee on the Rights of the Child, UNICEF, and the Bernard van Leer Foundation. A guide to general comment 7: implementing child rights in early childhood. The Hague (NL): Bernard van Leer Foundation; 2006.

5. Lachance $\mathrm{M}$, Cartwright $\mathrm{F}$, Boughton $\mathrm{C}$. Introducing the composite learning index In: Lloyd JEV, editor. Bringing it together: merging community-based, life-course, linked data, and social indicator approaches to monitoring child development. Proceedings from the Early Childhood Learning Knowledge Centre's Monitoring Committee Workshop. 2006 Sept 18-19; Toronto (ON). Montréal (QC): Canadian Council on Learning; 2008. p. 11-14. Available: www.ccl-cca.ca/NR/rdonlyres /A926804D-EA69-4C70-A2E4-224A734C0410/0/BringingItTogetherEN.pdf (accessed 2008 Dec 1).

6. Janus M, Offord DR. Development and psychometric properties of the Early Development Instrument (EDI): a measure of children's school readiness. Can J Behav Sci 2007;39:1-22.

7. Kershaw P, Irwin LG, Trafford K, et al. British Columbia atlas of child development. Vancouver (BC): UBC Press; 2006.

8. Human Early Learning Partnership. Vancouver: University of British Columbia; 2007. Available: www.earlylearning.ubc.ca (accessed 2008 Nov 12).

9. Boivin M, Lemelin JP, Forget-Dubois N, et al. Early child development and early school achievement: a test for the EDI, results from the Québec longitudinal study of child development. In: Lloyd JEV, editor. Bringing it together: merging communitybased, life-course, linked data, and social indicator approaches to monitoring child development. Proceedings from the Early Childhood Learning Knowledge Centre's Monitoring Committee Workshop. 2006 Sept 18-19; Toronto (ON). Montréal (QC): Canadian Council on Learning; 2008. p. 32-36. Available: www.ccl-cca.ca/NR /rdonlyres/A926804D-EA69-4C70-A2E4-224A734C0410/0/BringingItTogetherEN pdf (accessed 2008 Dec 1).

10. Roos NP, Brownell M, Guèvremont A, et al. The true story: A population-based perspective on school performance and educational testing. Can J Educ 2006; 29:1-22.

11. Lloyd JEV, editor. Bringing it together: merging community-based, life-course, linked data, and social indicator approaches to monitoring child development. Proceedings from the Early Childhood Learning Knowledge Centre's Monitoring Committee Workshop. 2006 Sept 18-19; Toronto (ON). Montréal (QC): Canadian Council on Learning; 2008. Available: www.ccl-cca.ca/NR/rdonlyres/A926804D-EA69 -4C70-A2E4-224A734C0410/0/BringingItTogetherEN.pdf (accessed 2008 Nov 20).

Correspondence to: Dr. Clyde Hertzman, University of British Columbia, Rm. 440, 2206 East Mall, Vancouver BC V6T 1Z3; clyde.hertzman@ubc.ca 